\title{
Colonoscopy: Early Experience in National Hospital Abuja Nigeria
}

\author{
Oluwole Olaomi, Onyedika Okoye, Oluwale Badejo
}

Department of Surgery, National Hospital Abuja, Abuja, Nigeria

Email address:

wole_olaomi@yahoo.com (O. Olaomi)

\section{To cite this article:}

Oluwole Olaomi, Onyedika Okoye, Oluwale Badejo. Colonoscopy: Early Experience in National Hospital Abuja Nigeria. International Journal of Gastroenterology. Vol. 4, No. 2, 2020, pp. 72-76. doi: 10.11648/j.ijg.20200402.18

Received: December 2, 2020; Accepted: December 10, 2020; Published: December 31, 2020

\begin{abstract}
Colonoscopy has become one of the most important modalities in the assessment of the lower gastrointestinal lesions. This study focused on our early experience with colonoscopy documenting the indications and outcome in the first five years of Colonoscopy in National Hospital, Abuja, Nigeria. This was a retrospective analysis of demographic data, indications for colonoscopy, agents used for bowel preparation, type of anaesthesia used, endoscopic findings, and extent of colon intubation from the endoscopy unit register of National Hospital, Abuja between July 2007 and June 2012. Patients whose data were incomplete or procedure abounded were excluded. Two hundred and eleven patients had colonoscopy during the 5 year period. Only 153 patients fulfilled the inclusion criteria and their data analysed. Males were 107 (69.9\%) and 46 (30.1\%) were females given a male/female ratio of 2.3:1 Age range was 2years to 90years with a Mean of 48.02. The commonest indications were bleeding per rectum $(33.3 \%)$, haemorrhoids $(24.8 \%)$ and suspicion of malignancy of the lower gastrointestinal tracts $(24.3 \%)$. The most common findings on colonoscopy in our study were haemorrhoids $(47.7 \%)$ and malignancies $(24.2 \%)$ of various parts of the large bowel. $12.4 \%$ of the patients had normal study. Our Ceacal intubation rate was 75.8\%. Majority of the lesions were found in the Anorectal region (69.9\%) with only $17.7 \%$ in the rest of the Colon $24.2 \%$ of our findings were malignancies of lower intestinal tract. $97.3 \%$ of the malignancies were Adenocarcinoma. $83.8 \%$ of the malignancies were located in the left colon. Assessment of lower gastrointestinal symptom is incomplete without colonoscopy. Colonoscopy gives a good yield in well selected patients, it is safe and has low complication rate.
\end{abstract}

Keywords: Colonoscopy, Experience, Lower Gastrointestinal, Haemorrhoids, National Hospital, Nigeria

\section{Introduction}

The examination of the colon with a flexible imaging tube (Colonoscope) is a standard procedure for some decades now. Fiberoptic endoscope was developed in mid- February 1957 [1]. Retrograde colonoscopy of the entire colon began in June of 1969 while endoscopic excision of polyps from the colon was first done in September of 1969 [2]. Since the beginning of Colonoscopy in June 1969, and endoscopic excision of polyps from the colon in September of same year, momentous advances have occurred over the years, and the two procedures are now widely accepted and practiced ${ }^{2}$. The facility for Colonoscopy is relatively rare in the developing counties. The first experience in Colonoscopy in Nigerian was by Arigbabu in Ile-Ife in 1978 [3]. The demand for colonoscopy has increased over the years because of increase in population, the relative safety and low complications of the procedure.

Colonoscopy helps to visualise the lumen of the entire colon to the distal terminal ileum, take biopsies, stop bleeding points, remove polyps and suspected colorectal lesions and mark the base of removed lesions for easy of identification during further interventions. Colonoscopy is now an essential procedure in the screening, diagnosis and treatment of lower gastrointestinal lesions. Colonoscopy is indicated for accurate diagnosis and treatment of lower gastrointestinal diseases in patients presenting with positive faecal occult blood, bleeding per rectum, unexplained changes in bowel habit and suspicion of malignancy [4].

Colonoscopy is the gold standard for colorectal cancer (CRC) screening [4]. The American cancer society 
recommends, starting lower GI endoscopy at the age of 50 years, for both men and women that they undergo a flexible Sigmoidoscopy every 5 years or a colonoscopy every 10 years [5]. People with a family history of colon cancer are often first screened during their teenage years. Colonoscopy screening prevents approximately two-thirds of the deaths due to colorectal cancers on the left side of the colon, and is not associated with a significant reduction in deaths from right-sided disease [6].

Many patients undergo colonoscopy in National Hospital Abuja for various indications yearly. There was no available data on Colonoscopy indications and findings from National Hospital Abuja. Therefore, this study was an analysis of indications for colonoscopy and findings in patients who presented with lower GI symptoms in the early years of endoscopy services in National hospital Abuja, Nigeria.

\section{Materials and Methods}

This is a retrospective analysis of the data of the endoscopy unit of National Hospital Abuja from July 2002 to September 2012. Colonoscopy started at this Unit in July 2007. National Hospital Abuja is a tertiary hospital which was established in 1999, located in the Central Business District of Abuja, the Federal Capital Territory of Nigeria and serves as a referral centre for the North-Central zone of Nigeria. The Endoscopy unit started in July 2002 and was the first endoscopy unit in Abuja.

Patients and Exclusion

A total of 578 patients had gastrointestinal endoscopy in National Hospital Abuja between July 2007 and June 2012 out of which 211 had colonoscopy. Data on patients who underwent colonoscopy were collected from the register. All patients who had incomplete data and those in which the colonoscopy was abandoned for any reason were excluded from the study.

Data were obtained from the Endoscopy register maintained in the Endoscopy unit. Recorded information included age, sex, indications for colonoscopy, agents used for bowel preparation, type of anaesthesia used, endoscopic findings, and extent of colon intubation. Biopsy was done as indicated and at the discretion of the Endoscopist. The data were analyzed and reported in the form of tables and graphs. Ethical approval was obtained from the Ethics Committee of the National Hospital Abuja.

\section{Results}

A total of 211 patients had colonoscopy during the 5 year period. Only 153 patients' data were analysed after removal of patients that fulfilled the exclusion criteria.

\subsection{Patient Characteristics}

There were 107 (69.9\%) males and 46 (30.1\%) females with a male/female ratio of 2.3:1 (Table 1). Age ranged from 2 years to 90 years with a Mean of 48.02 (Table 2).
Table 1. Sex Distribution.

\begin{tabular}{lll}
\hline & Frequency & Percent \\
\hline $\mathrm{F}$ & 46 & 30.1 \\
$\mathrm{M}$ & 107 & 69.9 \\
Total & 153 & 100.0 \\
\hline
\end{tabular}

Table 2. Age Group.

\begin{tabular}{lll}
\hline & Frequency & Percent \\
\hline$<=20$ & 2 & 1.3 \\
$21-30$ & 12 & 7.8 \\
$31-40$ & 29 & 19.0 \\
$41-50$ & 50 & 32.7 \\
$51-60$ & 38 & 24.8 \\
$61-70$ & 15 & 9.8 \\
$>=71$ & 7 & 4.6 \\
Total & 153 & 100.0 \\
\hline
\end{tabular}

\subsection{Indication}

Bleeding per rectum (33.3\%) was the commonest indication for colonoscopy followed by haemorrhoids (24.8\%) and suspicion of malignancy of various parts of the lower gastrointestinal tracts $(24.3 \%)$. The various indications for which colonoscopy was done are listed in Table 3 and indications segregated by gender are shown is Figure 1. 40.5\% of our indications are for the disease of Anorectal region.

Table 3. Indications.

\begin{tabular}{lll}
\hline & Frequency & Percent \\
\hline INFLAMMATORY BOWEL DISEASE & 5 & .3 .3 \\
ABDOMINAL MASS & 1 & .7 \\
ALTERED BOWEL HABIT & 11 & 7.2 \\
ANAEMIA & 2 & 1.3 \\
ANAL FISTULA & 13 & 8.5 \\
ANAL TUMOUR & 2 & 1.3 \\
BLEEDING PR & 51 & 33.3 \\
COLONIC TUMOUR & 14 & 9.2 \\
EXCESSIVE FLATULENCE & 1 & .7 \\
HAEMORRHOIDS & 38 & 24.8 \\
INTESTINAL OBSTRUCTION & 4 & 2.6 \\
LOWER ABDOMINAL PAIN & 1 & .7 \\
RECTAL TUMOR & 9 & 5.9 \\
SCREENING (+ family history) & 1 & .7 \\
\hline
\end{tabular}

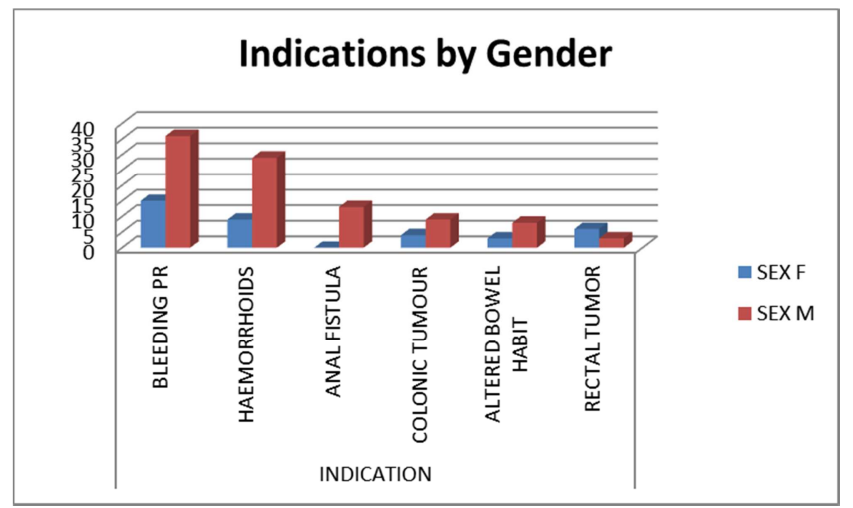

Figure 1. Indications for colonoscopy by gender.

\subsection{Sedation Agents}

All our patients had their procedure under conscious 
sedation using various combinations of anxiolytics (Diazepam or Midazolam) and Pentazosin or Propofol as shown in Figure 2. They were all monitored with Pulse rate, Blood pressure and Oxygen saturation measurements.

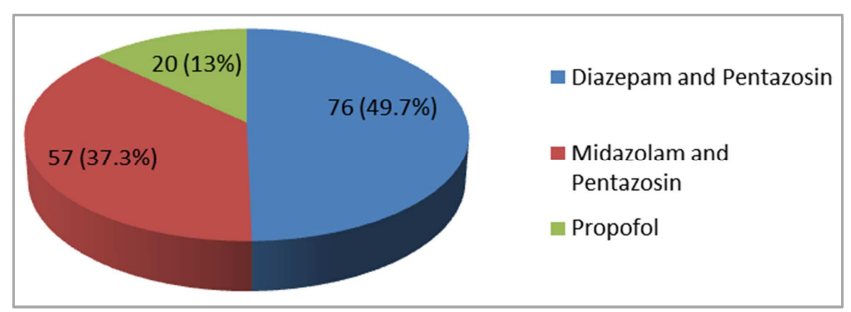

Figure 2. Sedation agents' distribution.

\subsection{Bowel Preparation}

All patients had one day bowel preparation a day prior to the procedure with low residue diet and purgative using either Castor oil or Mannitol (Figure 3).

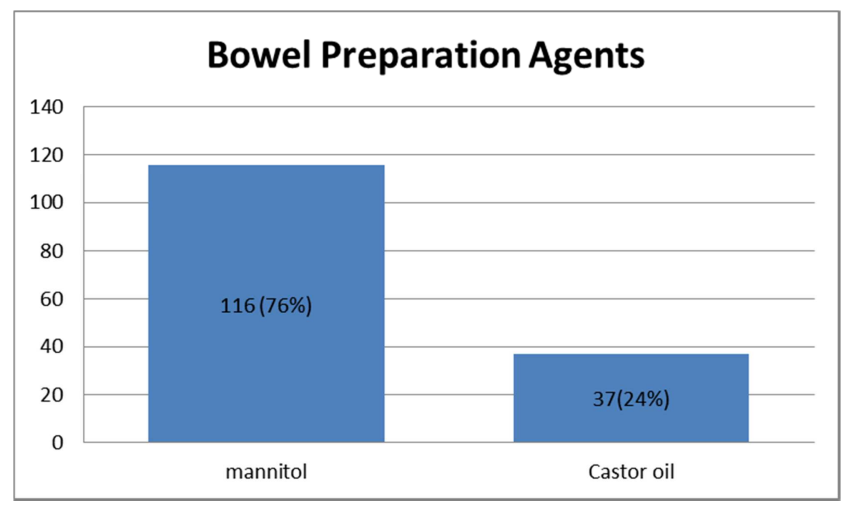

Figure 3. Bowel preparation agents.

\subsection{Colonoscopy Findings}

Table 4. Colonoscopy Findings.

\begin{tabular}{lll}
\hline & Frequency & Percent \\
\hline ANAL FISTULA & 13 & 8.5 \\
ANAL TUMOUR/Squamous & 2 & 1.3 \\
BLEEDING DIVERTICULITIS & 2 & 1.3 \\
COLITIS & 6 & 4 \\
COLONIC CA & 17 & 11.1 \\
DIVERTICULITIS & 1 & .7 \\
HAEMORRHOIDS & 73 & 47.7 \\
HIRSCHSPRUNG DX & 1 & .7 \\
NORMAL STUDY & 19 & 12.4 \\
RECTAL CA & 18 & 11.8 \\
SESSILE POLYP (ADENOMA & 1 & .7 \\
Total & 153 & 100.0 \\
\hline
\end{tabular}

Haemorrhoids were the most common finding on colonoscopy $(47.7 \%)$ in this study followed by malignancies $(24.2 \%)$ of various parts of the large bowel. Haemorrhoids ranked first in early age groups until after 60 years. Haemorrhoids and malignancy ranked top between ages 6170years after which malignancies were the most common finding. Carcinoma of the rectum was commoner in females in this study. $12.4 \%$ of the patients had normal study. Table 4 shows our findings on colonoscopy and the relative frequency, Figure 4 shows the findings by gender while Figure 5 shows findings by age groupings. Colonoscopy was done to the Ceacum in $116(75.8 \%)$ patients and was terminated in the Sigmoid colon in $20(13 \%)$ patients. Figure 6 shows the extent of intubation in our patients. Most of the lesions where found in the Anorectal region (69.9\%), Colonic lesions were $17.7 \%$ while $12.4 \%$ were normal. Colonoscopy diagnostic yield in this study was $87.6 \%$.

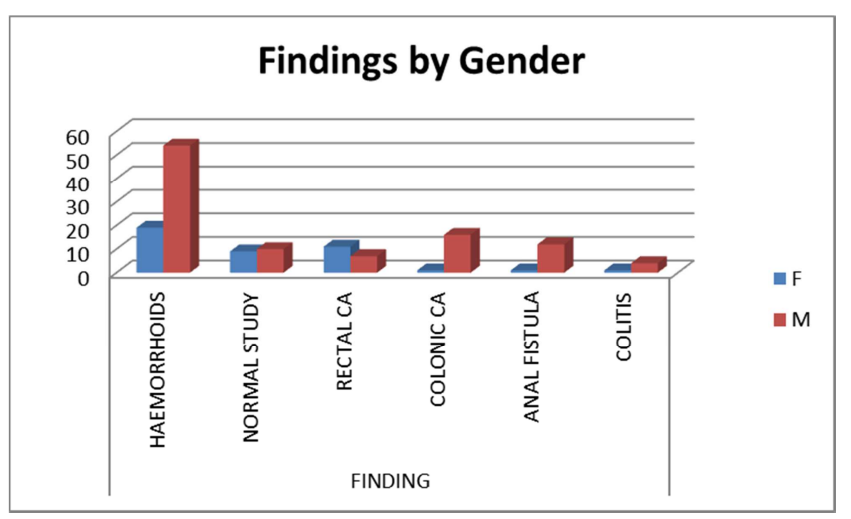

Figure 4. Colonoscopy findings by gender.

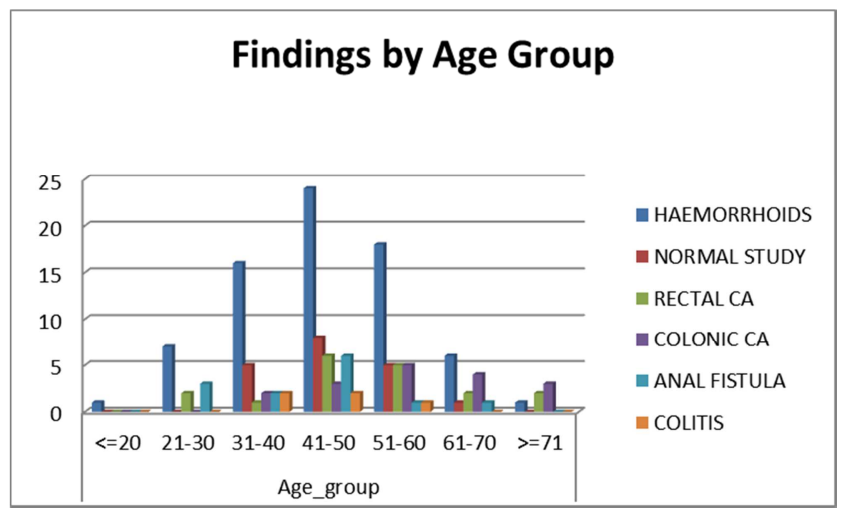

Figure 5. Colonoscopy findings by age group.

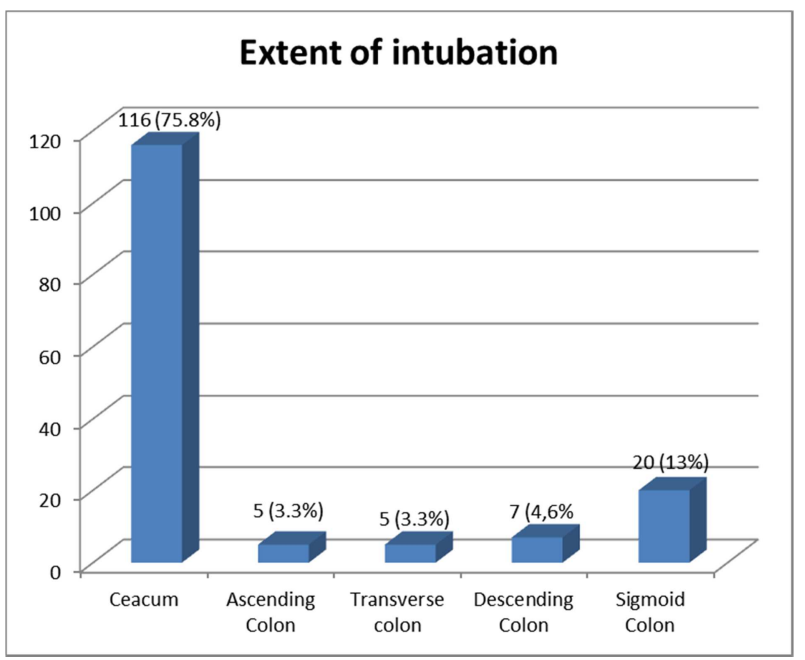

Figure 6. Extent of intubation.

$24.2 \%$ of our findings were malignancies of lower intestinal tract, $97.3 \%$ (36) of the malignancies were Adenocarcinoma while $2.7 \%$ (1) were Squamous Cell 
Carcinoma of the Anus. $83.8 \%$ of the malignancies were located in the left colon. Figure 7 shows the distribution of the malignancies along the colon. $75.8 \%$ of our outcome was benign lesions.

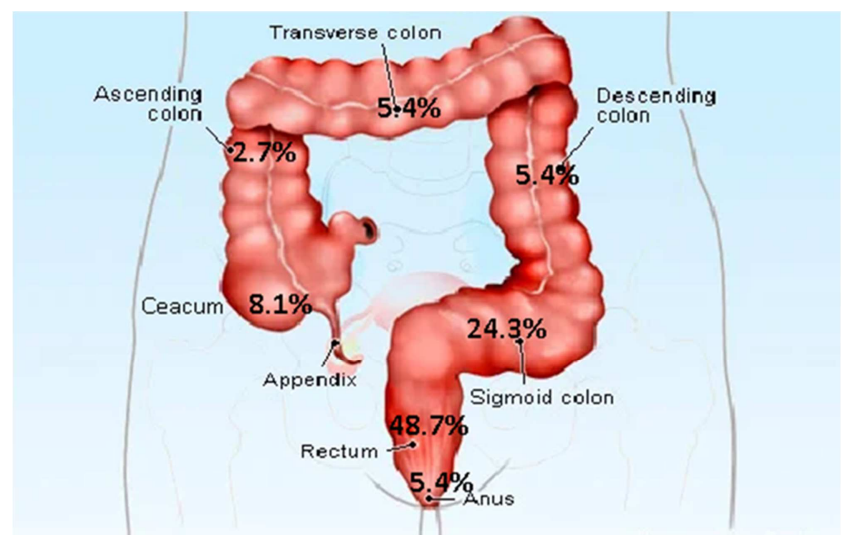

Figure 7. Locations of Malignant lesion.

\section{Discussion}

This study analysed the data of initial five years of colonoscopy practice in the National Hospital Abuja. The Male/ Female ratio of 2.3:1 is consistence with the reports of previous studies with a preponderance of male undergoing colonoscopy [7-9].

The commonest indication for colonoscopy was bleeding per rectum in $33.3 \%$ followed by haemorrhoids (24.8\%) and suspicion of lower GI malignancy $(24.3 \%)$ in this study. Bleeding per rectum was also the commonest indication in other studies in Nigeria and other parts of the world [7-12]. This may be due to the fear that is associated with passing blood from the anus which sensitize the patients that something is not right and make the patients to seek immediate medical help. However in a study by Ogutu [13] that involved colonoscopy in only Kenyans, abdominal pain $(35.6 \%)$ was the commonest indication while rectal bleeding $(19.8 \%)$ was the fourth most common indication. Abdominal pain was very low down in the order of indications in our patients; this may suggest that abdominal pain is not consider as a serious symptom to warrant colonoscopy in this environment.

The choice of sedation agents was dependent on the preference of the endoscopist and the availability of Midazolam. The few patients who had Propofol were patients in whom difficult procedure was envisaged and prior arrangements were made for anaesthesiologist to be present for the procedure. The use of Castor oil and $10 \%$ or $20 \%$ Mannitol was because of non-availability of Picolax, Polyethylene glycol and other suitable cathartics in Abuja when colonoscopy started at National Hospital. 76\% usage of Mannitol to $24 \%$ usage of Castor oil reflects operators' preference for Mannitol over castor oil. We had adequately cleansed colon using castor oil or Mannitol in our patients but the large volume of fluid taken orally by patients to prevent dehydration, non-palatable taste and oily reflections of castor oil and the risk of explosion after mannitol administration during colonoscopy-polypectomy using energy devise $[14,15]$ were the draw backs to using these agents.

Haemorrhoids were the most common findings on colonoscopy $(47.7 \%)$ in this study; this is consistent with findings of Alatishe [9] and Onyekwere [12] in Nigeria and Dakubo [16] in Ghana who had haemorrhoids as their most common findings while it was second commonest in the studies by Obinna [8] and Akere [11]. Dakubo [16] also found colorectal malignancies as the second most common lesions as we found in Abuja. Majority of lesions were on the left side including $78.4 \%$ of the malignancies in our study, this means sigmoidoscopy which requires lower expertise than colonoscopy will be able to diagnosis these lesions. Dakubo [16] and Ray-Offor [17] reported similar dominance of left sided lesions in their studies also, Dakubo [16] reported $95.3 \%$ of tumours in their study was found during sigmoidoscopy and only $4.7 \%$ on colonoscopy while $66 \%$ of yield in Ray-Offor's [17] study were in the anorectum and sigmoid colon. In a multi-centred study in United Kingdom by Moug et al [18] 58\% of lesions during colonoscopy were from the splenic flexure to the rectum with $57.9 \%$ confirmation of these locations by surgery.

Caecal intubation rate (CIR) in this analysis was $75.8 \%$. This is lower than the ASGE guildeline [21]. This is also low compared with the studies by Osinowo [20] (80.2\%), Onyekwere [12] (81.2\%) and Akere [19] (97.5\%). This may be due to the low volume of colonoscopy at this centre at the onset of colonoscopy, use of conscious sedation which does not give better anaesthesia compared to Propofol and agents of bowel preparation which is less tolerated by the patients and may result in relatively less satisfactory bowel preparation compared to Polyethelene glycol and Picolax which are less cumbersome and more effective than mannitol and castor oil.

Our colonoscopy diagnostic yield was $87.6 \%$; this is more than the diagnostic yield by Ray-offor [17], Obinna [8] and Osinowo [20]. This may be because majority of our patients are above 40years and many of them were referred by specialists which may mean better patient selection in our study therefore resulting in higher diagnostic yield.

\section{Conclusion}

Colonoscopy is now an important examination in the workup of patients presenting with lower gastrointestinal symptoms. As seen in our study the yield is high $(87.6 \%)$ compared to $12.4 \%$ of normal findings which can be further increased by good patient selection. Bleeding per rectum was the commonest indication in for colonoscopy in Abuja while haemorrhoids followed by Malignancies were the common colonoscopy findings. Colonoscopy has gained prominence over Barium enema over the years because lesions are better visualised, biopsy can be taken, it has therapeutic benefits for removal of polyps and small lesions and it is relatively safe with low complications as since in our study where no 
complication was recorded.

\section{References}

[1] Basil I. Hirschowitz, A Personal History of the Fiberscope Gastroenterology 76: 864-869, 1979.

[2] Wolff WI Colonoscopy: history and development. Am J Gastroenterol. 1989 Sep; 84 (9): 1017-25.

[3] O. Arigbabu and W. O. Odesanmi, "Colonoscopy. First experience in Nigeria," Diseases of the Colon and Rectum, vol. 28, no. 10, pp. 728-731, 1985.

[4] Multi-Disciplinary Taskforce, New consensus colorectal cancer screening guidelines, Gastroenterology, May 2008.

[5] American Cancer Society Guidelines for the Early Detection of Cancer. http://www.cancer.org/healthy/findcancerearly/cancerscreenin gguidelines/ american-cancer-society-guidelines-for-the-earlydetection-of-cancer.

[6] Baxter NN, Goldwasser MA, Paszat LF, Saskin R, Urbach DR, Rabeneck L. Association of colonoscopy and death from colorectal cancer. Ann Intern Med 2009; 150: 1-8.

[7] Oguntoye Oluwatosin Oluwagbenga, Yusuf Musah, Olowoyo Paul, et al. Colonoscopy in Ido-Ekiti, Nigeria: A Four-Year Review. Gastroint Hepatol Dig Dis. 2020; 3 (1): 1-8.

[8] Obonna GC, Arowolo AO, Agbakwuru A. Experience with Colonoscopy in the Riverine Southwestern Nigeria. J West Afr Coll Surg. 2012; 2 (2): 80-90. [PubMed] [Google Scholar].

[9] Alatise $\mathrm{OI}^{1}$, Arigbabu AO, Agbakwuru EA, Lawal OO, Ndububa DA, Ojo OS Spectrum of colonoscopy findings in Ile-Ife Nigeria. Niger Postgrad Med J. 2012 Dec; 19 (4): 21924.

[10] Dinesh HN, Shashidhar HB, Prasad V. An Analysis of Colonoscopy Findings in a Tertiary Care Hospital. Int J Sci Stud 2015; 3 (7): 212-216.
[11] Akere A, Oke TO, Otegbayo JA. Colonoscopy at a tertiary healthcare facility in Southwest Nigeria: Spectrum of indications and colonic abnormalities. Ann Afr Med 2016; 15 (3): 109-13.

[12] Onyekwere CA, Odiagah JN, Ogunleye OO, Chibututu C, Lesi OA. Colonoscopy practice in Lagos, Nigeria: a report of an audit. Diagn Ther Endosc 2013; 798651.

[13] Ogutu EO, Okoth FA, Lule GN. Colonoscopic findings in Kenyan African patients. East Afr Med J. 1998; 75: 540-543.

[14] Taylor EW, Bentley S, Youngs D, Keighley MRB. Bowel preparation and the safety of colonoscopic polypectomy. Gastroenterology 1981; 81: 1-4.

[15] Spiros D Ladas, George Karamanolis, and Emmanuel BenSoussan Colonic gas explosion during therapeutic colonoscopy with electrocautery. World J Gastroenterol. 2007 Oct 28; 13 (40): 5295-5298.

[16] Dakubo JC, Seshie B, Ankrah LN. Utilization and diagnostic yield of large bowel endoscopy at Korle-Bu Teaching Hospital. J Med Biomed Sci. 2014; 3: 6-13 [Google Scholar].

[17] Ray-Offorf E, Ibeanusi SEB (2018) Diagnostic Yield of Colonoscopy. J Clin Gastroenterol Hepatol Vol. 2 No. 2: 11. doi: $10.21767 / 2575-7733.100040$.

[18] Moug SJ, Fountas S, Johnstone MS, Bryce AS, Renwick A, et al. (2017) Analysis of lesion localisation at colonoscopy: Outcomes from a multi-centre U.K. study. Surg Endosc 31: 2959-2967.

[19] Akere A, Akande K O. Cecal intubation rate during colonoscopy at a tertiary hospital in South-West Nigeria: How frequent and what affects completion rate?. Niger J Clin Pract 2017; 20: 303-6.

[20] Osinowo A, Lawal O, Lesi OA, Olajide T, Adesanya A. Audit of colonoscopy practice in Lagos University Teaching Hospital. J Clin Sci 2016; 13: 29-33.

[21] Davila RE, Rajan E, Baron TH, Adler DG, Egan JV, Faigel DO, et al. ASGE guideline: Colorectal cancer screening and surveillance. Gastrointest Endosc 2006; 63: 546-57. 